\title{
Sustainable technology transfer for poverty alleviation: a unified framework for challenges and transdisciplinary solution approaches
}

\author{
J. Bendul ${ }^{1}$, E. Rosca ${ }^{1} \&$ T. Hoffmann ${ }^{2}$ \\ ${ }^{I}$ Department of Mathematics and Logistics, Jacobs University, Germany \\ ${ }^{2}$ Consultant in Renewables Engineering, Bremen, Germany
}

\begin{abstract}
Technology transfer has been identified as a means for poverty alleviation for decades. Nevertheless, technology transfer projects from industrialized to developing countries have failed repeatedly. Technology transfer projects within the development cooperation area comprise various challenges under economic, environmental, social, institutional and technical dimensions. Inappropriate technology, operation and maintenance issues and lack of socio-cultural entrenchment of the transferred technologies are the most often cited reasons for project failure. Scholars argue that transfer methodologies are more important than the technology itself and it should incorporate aspects and methods from various disciplines such as project management, production, marketing and business innovation in order to ensure sustainable technology transfer and poverty alleviation. In this sense, the aim of this paper is to develop a conceptual framework which outlines the main challenges and transdisciplinary solution approaches for the sustainability of technology transfer projects for poverty alleviation in developing countries from practical and theoretical perspectives. The methodological design consists of literature review combined with experts' interviews with specialists in technology transfer projects around the world from a specialized NGO. The findings reveal best practices and problems from a highly advanced technology transfer organization in terms of localized technical solutions and agile integrated planning approaches. Yet, the social and institutional aspects remain largely complex and difficult to solve. The recommended transdisciplinary approaches include sustainable business model development, frugal re-engineering methods and agile project management.
\end{abstract}

Keywords: technology transfer, developing countries, sustainable development, principal-agent theory, business model development, agile project management. 


\section{Introduction}

Technology transfer (TT) from industrialized to developing countries has the potential to bridge the gap between standard of living in different areas worldwide [1-3]. Various stakeholders such as NGOs, governments and corporations have been undertaking initiatives to alleviate poverty through TT and diffusion among communities through the past decades. Nevertheless, there are still more than one billion people still living on less than $\$ 1.25$ per day as of 2011 [4]. Numerous amounts of aid from developed countries attempt to transfer technology to offer basic poverty alleviation services such as sanitation, wastewater treatment, solid waste management, faecal sludge, water and energy supply. Nonetheless, many of these development initiatives still fail in the long-run mainly because their implementation fails to establish favourable conditions for the technology and the service provided to prosper in the long-run [5]. In fact, Reymond [6] claims that failure is the rule rather than the exception. Repeated failures in development projects have been caused by inappropriate technologies, lack of user centricity, lack of endogenous capabilities in regard to Operation and Maintenance (O\&M) and lack of adequate financing models.

With reference to the abovementioned, this paper has the following objectives. Firstly, it attempts to collect and analyse various empirical studies from the literature which systematically investigate the causes of lack of sustainability in TT projects. Secondly, it employs a Principal-Agent (P-A) theory perspective in order to understand the problem and the underlined theoretical solutions. Thirdly, it employs an experts interviews approach to explore in-depth the dynamics of TT projects in the development cooperation field, best practices, frequent causes of failure and requirements for solution approaches. Fourthly, it aims to provide recommendations for transdisciplinary solution approaches and combine the findings in a framework. From a practical perspective, the insights are of relevance to all stakeholders involved directly or indirectly in TT projects in development cooperation area.

This paper is organized as follows: Section two provides a brief theoretical background reviewing empirical studies on TT in development cooperation field, existing solutions and their limitations, and theoretical foundations of the P-A theory, Section three describes the employed methodology, while Section four presents and discusses the findings. Section five covers conclusions and further research recommendations.

\section{Literature review}

\subsection{Technology transfer definition and enabling factors}

Traditionally, TT has been understood as the physical transfer of technologies from industrialized to developing countries [7]. However, TT involves more than just the transfer of hardware components, it includes elements of how to adapt, integrate, improve, commercialize, maintain and operate technologies [7]. 
Therefore, for the scope of this research, we adopt a broad definition of TT in order to encompass for different sizes, scopes and complexity of development cooperation projects. Thus, TT is defined as 'the broad set of processes covering the flows of knowledge, experience and equipment amongst different stakeholders such as governments, private sector entities, financial institutions, NGO's and research/educational institutions' [8]. Although TT projects vary largely in size, complexity and scope and thus the enabling factors would be different, scholars did find several common elements of successful TT projects. Liu and Liang [9] argue that successful TT includes besides physical transfer of technologies, local capacity building, financing mechanisms and monitoring systems. As such, the primary objective of TT is to develop local capabilities, enhancing poverty alleviation through development and innovation [9].

In this paper, we define sustainable TT in terms of projects' ability to financially sustain themselves, fulfill users' needs, promote environmental protection and provide appropriate technical solutions. The aspects are elaborated as follows: 1) Economic - low initial investments, low O\&M costs, appropriate financing models for before and after implementation stages; 2) Social \& Institutional - acceptance and ownership by locals, user centricity, incorporation of cultural/religious practices, development of the user's skills and capabilities through training and education, increasing awareness, local support of governments and institutions, supporting public policies; 3) Environmental - risk of infection, low usage of resources, low ecological harm; 4) Technical - low complexity, high flexibility, compatibility with other local systems, locally available components.

\subsection{Lack of sustainability in TT development cooperation projects}

TT projects from industrialized to developing countries, also known as horizontal TT have been reportedly failing for various reasons which include inadequate understanding of local needs, high transaction costs or lack of local acceptance. An extensive literature review has been performed in order to identify empirical studies which investigate the reasons for the failure of TT projects in the area of international development cooperation. The findings are in Table 1.

As development cooperation aims to alleviate poverty and improve the standard of living in developing countries, most TT projects are related to provision of basic services such as water, sanitation, wastewater treatment, faecal sludge management (FSM) and energy supply. Although the studies in Table 1 are from various geographical locations and refer to different types of project in terms of size and complexity, they revealed very consistent patterns across different cases of TT. The main problems and causes of TT projects failure in the area of development cooperation are discussed on the four dimensions of sustainability. From an economic perspective, investment costs are posing challenges for the initial stages project planning and implementation, however, O\&M, reinvestment, energy costs are posing severe barriers for the long-term project survival. Often, users find it difficult to pay for the services and there is a lack of 
Table 1: Empirical studies on TT development cooperation projects.

\begin{tabular}{|c|c|c|c|}
\hline Study & Type of Projects & Location(s) & Failure Causes \\
\hline $\begin{array}{l}\text { Klintenberg } \\
\text { et al. }[10]\end{array}$ & Renewable energy & $\begin{array}{c}\text { Botswana \& } \\
\text { Namibia }\end{array}$ & $\begin{array}{c}\text { O\&M issues, users' difficulty to pay } \\
\text { for services, strong focus on } \\
\text { technology. }\end{array}$ \\
\hline $\begin{array}{l}\text { Terrapon-Pfaff } \\
\quad \text { et al. }[5]\end{array}$ & Renewable energy & Worldwide & \begin{tabular}{|} 
Unsuitable technology, external \\
negative influences, lack of users' \\
motivation, lack of local capacity to \\
manufacture and maintain \\
technology.
\end{tabular} \\
\hline Sianipar et al. [2] & $\begin{array}{l}\text { Basic poverty } \\
\text { alleviation projects }\end{array}$ & Indonesia & $\begin{array}{l}\text { Inappropriate technologies, top- } \\
\text { down approach to local needs, low } \\
\text { technological diffusion, weak } \\
\text { acceptance from users. }\end{array}$ \\
\hline Strande et al. [11] & $\begin{array}{l}\text { Faecal sludge } \\
\text { management, waste } \\
\text { water treatment }\end{array}$ & Worldwide & \begin{tabular}{|} 
Lack of integrated system approach, \\
lack of capacity building and \\
empowerment, no involvement in \\
the planning process of the key \\
stakeholders, weak O\&M, \\
inappropriate financial schemes, \\
lack of cost-recovery mechanisms.
\end{tabular} \\
\hline $\begin{array}{c}\text { Nikiema et al. } \\
{[12]}\end{array}$ & Wastewater treatment & $\begin{array}{l}\text { Seven African } \\
\text { Countries }\end{array}$ & $\begin{array}{c}\text { Poor O\&M, high energy costs, lack } \\
\text { of re-investments, limited local } \\
\text { acceptance and willingness to pay } \\
\text { for the services, environmental } \\
\text { risks, and low performance of } \\
\text { technology. } \\
\end{array}$ \\
\hline Starkl et al. [13] & Water and sanitation & $\begin{array}{l}\text { India, Mexico, } \\
\text { South Africa }\end{array}$ & $\begin{array}{c}\text { Hygienic risks, O\&M problems, } \\
\text { technical and social risks, } \\
\text { inappropriate technologies, lack of } \\
\text { local support. }\end{array}$ \\
\hline $\begin{array}{l}\text { Schillebeeckx } \\
\text { et al. }[14]\end{array}$ & Energy supply & Worldwide & $\begin{array}{c}\text { Focus on technology and } \\
\text { institutions, viability of technology } \\
\text { and user involvement not } \\
\text { considered. }\end{array}$ \\
\hline $\begin{array}{c}\text { EU Commission } \\
{[15]}\end{array}$ & Water and sanitation & $\begin{array}{c}\text { Six Sub-Saharan } \\
\text { Countries }\end{array}$ & $\begin{array}{l}\text { Institutional weaknesses, ineffective } \\
\text { use of sustainability project } \\
\text { management tools, lack of non-tariff } \\
\text { revenue to support O\&M. }\end{array}$ \\
\hline Murphy et al. [3] & Water and sanitation & $\begin{array}{c}\text { Bangladesh, } \\
\text { Guatemala, Nepal }\end{array}$ & $\begin{array}{l}\text { End-users are not involved in the } \\
\text { development process, the } \\
\text { engineering approach does not } \\
\text { consider social, cultural and gender } \\
\text { aspects, focus on technology rather } \\
\text { than transfer mechanisms. }\end{array}$ \\
\hline
\end{tabular}

non-tariff revenue to ensure O\&M. Similarly, from an environmental perspective, ecological risks are high especially because the transferred technologies often behave unexpectedly in new environmental conditions. From a technical perspective, the technologies transferred are still found to be too complex and unable to fulfil users' needs in the long-run. The most encountered problem by far is related to the social dimension. There is a strong focus on technology and a lack of user involvement in the early development and planning stages. This has been usually known as 'the traditional engineering approach' which fails to incorporate 
social and cultural aspects [3]. This results in inappropriate technologies, low acceptance and support by locals and insufficient endogenous capacity building. The most often employed top-down approach cannot account for the very different local realities and settings of developing countries where most frequently the barriers lie $[2,6]$.

\subsection{Existing approaches and their limitations}

With the rise of Information and Communication Technologies (ICT), which provide a platform for information exchange between people across the world, several solutions for sustainable TT projects have been proposed [1]. For instance, the Open Source Movement enables technologies to be designed as free and open source, developed and licensed in such a way as to allow their designs to be used, modified and distributed freely [1]. Central resources and forum for collaboration such as Appropedia [16] have been providing access to design specifications of technologies for water, energy, health and many other basic services for poverty alleviation. In the specialized area of water and sanitation solutions, Akvopedia [17] is a portal for online knowledge on smart, low-cost, sustainable water and sanitation technology approaches. On the same line, the available design specifications of various technologies and the emergence of open source 3D printing could enable the self-sustained progress of developing countries by producing cheap, simple technologies with locally available materials and which meets the user's needs. Nevertheless, the success of the Open Source Movement is limited in the immediate future mainly because internet access and awareness in developing countries is very low. In the 2nd quarter of 2014, an Internet penetration of $42.3 \%$ worldwide was registered, while the average Internet penetration in Africa was 26.5\% [18]. Moreover, the Open Source Movement alone cannot effectively solve the poverty issue as it needs an effective enabling environment where social, institutional and economic factors play critical roles.

\subsection{A principal agent theory model of TT projects}

The P-A relationship denotes a structure of a principal and an agent who are engaged in a cooperative behaviour, but have diverging interests, significant information asymmetries and differing attitudes towards risk [19]. The theory suggests models the relationship between the principal giving the task and the agents hired to perform it while revealing the issues which may arise in the case of information asymmetries and self-interested agents. The P-A theoretical framework has been already used by development economist to examine the nature and relationships under the foreign aid chain and involved actors [20]. Development economists have recognized the complex network of stakeholders involving governments, private sector, NGOs and local users where every group has its own interest, motivation and constraints [21]. Therefore, the P-A theory is also very suitable for the study of TT in development cooperation settings where similarly numerous groups of stakeholders involved at different project stages and with diverse motivations have to perform a task delegated by the principal. The P-A theory is especially useful for the suggested theoretical solutions which can 
be selected according to different scenarios of assumptions. Overall, the P-A theory proposes different forms of solutions all based on incentives alignment: 1) monitor agent's behaviour through the means of information systems, 2) behaviour- or outcome-based reward depending on the task programmability or outcome uncertainty [19].

\section{Methodology}

This study aims to explore the reasons of TT failure in the field of international development cooperation and what are potential transdisciplinary solutions for this problem. Therefore, the emphasis is on 'why' and 'how' type of questions. Therefore, a case study approach is suitable for this research [22]. The case adopted is Bremen Overseas Research and Development Association (BORDA) a specialist organization based in Bremen, with more than 35 years of experience in TT projects in developing countries [23]. BORDA focuses its activities in the areas of decentralized sanitation, water and regenerative energy supply as well as wastewater and solid waste management solutions. BORDA is a suitable candidate for the aforementioned research question and its experiences are generalizable because it has an extensive experience in the field, its network spans worldwide projects of different sizes, complexities and themes and it operates both as an external knowledge provider and implementation guide. The data is collected through eight semi-structured interviews with experts from all around the world within the BORDA network and the findings are aggregated in a conceptual framework related to 'why' development projects fail and 'how' could this be prevented in the future. The semi-structured interview contained three main sections: 1) TT projects in operations - initial problems, sustainability indicators and critical success factors, 2) failed TT projects - systematic investigation results and experiences, 3) solution approaches needed. Interviews lasted around one hour and followed the initial guiding questions, then continued with in-depth questions in specific directions of interest. Experts interviews is a preferred approach for this study because TT projects often fail due to aspects difficult to quantify and experts' experiences can describe in-depth the TT processes and difficulties encountered.

\section{Findings and discussion}

\subsection{Problems and best practice solutions at BORDA}

As a technology-transfer expert, BORDA has realized a while ago that the local settings of developing countries are totally different than the industrial ones and there is a need for localized solutions. Subsequently, BORDA managed to employ global knowledge in local context, provide customized decentralized solutions. The interview experts found that finding sustainable solutions for TT is especially complex due to the interconnected nature of existing problems where an integrated system approach is needed. 
From a technical perspective, BORDA offers decentralized solutions for wastewater, solid waste, regenerative energy and water supply which are characterised by low investment and maintenance costs, use of only locally available materials, modular and long-lasting design. Yet, technological problems still appear mainly due to social aspects such as misuse of systems or opportunistic behaviour from the system operators. In this scenario, strong enforcement of regulations by the local authorities is needed to ensure long-term survival and effective operation.

From an economic perspective, BORDA's experiences show large differences in financing models across countries. Firstly, the source of initial investments determines the dynamics of the TT projects overall because the governments are easier engaged once there is public money involved, while they do not have any incentive to participate in O\&M of projects once the funds come from external foreign aid agencies. This means that in countries where no public money is available, involvement of the local authorities in the planning and implementation phases is very difficult. Secondly, while the literature suggests that in many cases the users cannot afford to pay the fees needed for O\&M, BORDA's experiences show that this is not a serious issue in the case of highly engaged communities. For instance, in many cases users can pay in products or by providing services. In worst cases when some users cannot really afford to pay, the other community members fill in the gaps by providing additional funds. Moreover, experience has shown that when people are convinced of the need and importance of the service, most users are willing to contribute. However, this is not the regular case and consequently, it all comes down to the social aspects and the involvement, the commitment of local communities. The engagement of communities is often determined by the community leaders, especially where communities are structured in social hierarchies or tribal structures. People take note on what the community chief/leader say and act accordingly, therefore, the reliability of the leader often determines the survivability of the project. Regular communication with the operator and with the community which is critical especially after implementation can only be done locally, by community leaders or governments. The multifaceted problem of ownership is highlighted, especially in the case of community based solutions. Whoever owns and is responsible for the system determines the long-term survivability of the project. In order to account for this problem, BORDA came up with a new, integrated planning approach $O W N I T$. $O W N$ IT is based on iterative joint development of local technical solutions according to demands of local stakeholders with the focus of local ownership.

Communities can also be incentivised by providing them with valuable resources which result from the sanitation or wastewater treatment plants such as water for irrigation, biogas for cooking or fertilizers for agriculture. This strategy has been largely employed by BORDA especially in the case of FSM projects.

Community and government involvement is especially difficult in the case of decentralized wastewater treatment projects because it is conceived as a rather sensitive topic. Therefore responsibilities are left undefined which often results in high project uncertainty. As previously said, institutional support is paramount 
in these scenarios as communities cannot work alone in the long-run. For instance, one of BORDA's FSM projects, which was completely planned, was interrupted during the start of construction because of elections. The opposition party boycotted the project, because it was supported by the ruling party. Cases like this are difficult to forecast in terms of sustainable TT.

An example of great community involvement coupled with institutional support is the unique after implementation service provider model of AKSANSI association in Indonesia. AKSANSI [24] is an association of over 600 communities who pay membership fee and in return receive support in operating and maintaining their decentralized wastewater treatment facilities through continuous monitoring, call-centres, specialized task force, lobbying with the government and any other emerging social issues. The AKSANSI model is unique within the BORDA network and it exemplifies best practise on how sustainability of TT projects can be achieved.

Altogether, BORDA's experiences underline the highly complex and interrelated social, institutional, economic and environmental realities in developing countries. This defines the need for a system-level solution approach which should encompass multitude levels of involvement, collaboration and empowerment.

\subsection{Recommended transdisciplinary solution approaches}

The interview and literature review findings for the main challenges are aggregated in the framework from Figure 1. Furthermore, based on the challenges, the main requirement for the solution approach has been defined as the need for integrated approach with aligned incentives of main stakeholders. The integrated system-level approach is required due to the interrelated nature of various technical, environmental, economic, social and institutional factors. The incentive alignment solution is suggested by the P-A theoretical solutions and it aims to encourage all stakeholders to work for the entire project aims.

In order to ensure a system-level integrated approach, the agile project management concept adopted from the software industry is recommended. Agile project management comprises a set of methods and techniques which is based on iterative and incremental development and in which requirements and solutions evolve through collaboration. Agile project management emerged from the software development industry mainly because of problems of high uncertainty and unpredictability of software development projects. However, later on it started to be employed in various other industries especially in environments in which the requirements are unknown or change quickly. Agile project management enables participatory approach and the incorporation of customer's requirements at an early stage in the product development. The four principles of agile project management are: 1) individual and interactions over processes and tools, 2) functioning technology over extensive documentation, 3) user collaboration over contract negotiations, 4) quick adjustment to change over rigid plans [25]. These principles make agile project management very suitable for the TT development cooperation projects. Agile project management is especially suitable for TT 


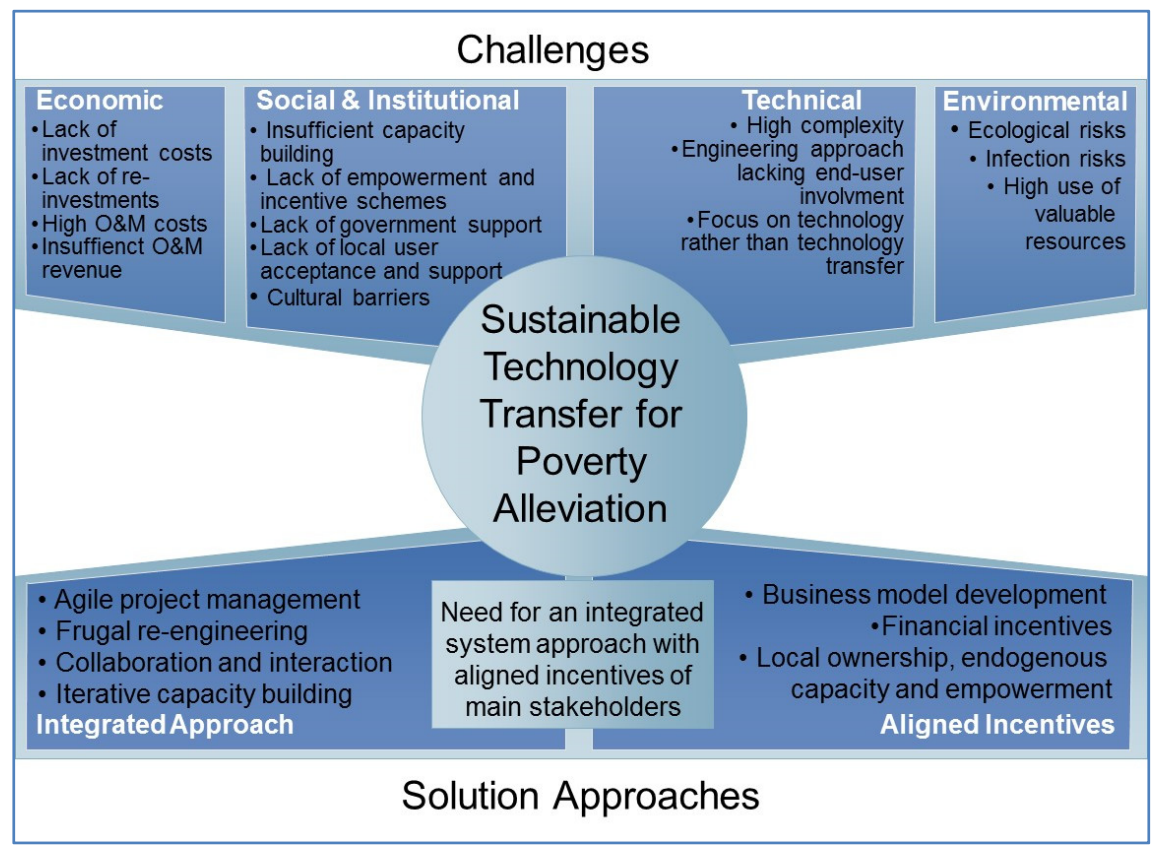

Figure 1: Framework of challenges and solution approaches.

development cooperation projects because the user's requirements will not be completely known only after the users have used the system. The agile project management should incorporate guidelines for innovation, implementation, education, promotion, sustainability, acceptance and governance of technology within development projects. The agile project management should integrate also frugal re-engineering methods and techniques to ensure that the transferred technologies are customized according to the local requirements. Frugal reengineering is a structured, sustainable process of continuously redesigning products to cut costs [26]. Usually this refers to removing nonessential features from a durable good such as car or phone, in order to sell it to developing countries. Cost effective continual re-engineering of a product is the essence of frugal reengineering. Frugal re-engineering encompasses four main elements: 1) the essential features valued by the target customers, 2) the optimized design in terms of size, weight and characteristics, 3) the simplification of manufacturing processes through the use of new technologies and 4) the substitution of expensive materials.

In order to ensure alignment of key stakeholders for the sustainability of TT projects, business model development method is recommended. It is largely accepted by growth economists that economic growth is a significantly more effective instrument for poverty alleviation in the long-run than foreign aid [27]. Also, it is acknowledged that at the core of economic growth is technological advancements and business development which are driven by entrepreneurial initiatives [27]. Consequently, one proposed way of enabling local ownership, 
endogenous capacity and empowerment while strengthening the local economy and improving user's possibility of paying for the provided services is business model development and local entrepreneurship. Initial preliminary findings suggest that this could be a viable option. For example, renewable energy projects in Botswana have managed to implement several local businesses related to procurement, production, distribution and service provision by locals [10]. The sustainable business model development field has already research in regard to how can companies develop and innovate their business models. Scholars have found empirical patterns and archetypes of sustainable business models which are applicable regardless of geographical or cultural elements [28]. Therefore, development cooperation field could enhance its knowledge base with methods and tools on how to develop new sustainable business models for different stages of the value chains.

\subsection{Discussion}

The literature review combined with the findings from the experts' interviews has highlighted the main challenges TT projects in developing countries face. The problems often cited in the literature include inappropriate technology, lack of investments, O\&M issues and local social acceptance. Our experts' interviews presents an advanced association encompassing localized technical solutions and agile TT approaches. Yet, the interconnected and highly complex in nature social and institutional aspects entail serious challenges for TT poverty alleviation projects. One has to understand the different socio-cultural-institutional settings of each community in order to adjust the planning approach to the local context. A system-level planning approach combined with an incentive based model as suggested by the P-A theory is needed. Traditionally, P-A structures refer to dyadic relationships. Yet, the complex setting of international development cooperation involves multiple principals and multiple agents each with differing interests, goals and demands. From the principal's perspective, donor organizations and local public agencies should behave as a collective principal with the same goals and interests. But, empirical findings suggest that donor organizations often entail hidden agendas while the corruption, multiple layers of influence and decision-making marks local agencies with diverging objectives within [20]. In the case of externally funded TT projects, the local authorities are very difficult to engage and thus the principal becomes the external agency. This is problematic especially because the principal is supposed to remain involved and monitor the project O\&M. Post-implementation monitoring and support is very difficult to be done by external agents and without the support of national or local laws and regulations. From an agent perspective, one distinguishes between shortterm contractors and long-term operators and service providers. Often the contractors hired for short-term tasks regard the donor organization as their principal and thus they are discouraged to act in the beneficiaries' interest, hiding critical information [21]. Also, there is a lack of sustainable models for operators and service providers in the case of complex TT projects such as sanitation, waste water treatment of FSM. Especially in this case the business model development has potential to provide financial incentives to key actors in the O\&M activities. 
The integrated approach combined with incentives alignment should be further investigated, developed into scalable and systematic steps and tested on the field.

\section{Conclusion}

This research aims to provide an overview of recurrent causes in TT projects' lack of sustainability. As shown by the literature review and the example of BORDA, development cooperation TT has made significant progress in the past years and they are learning more and more about how to approach communities, how to plan and to integrate relevant stakeholders. There are many successful stories which can serve as motivator and enabler for further successes. Nevertheless, the investigation found that social and institutional challenges remain largely problematic and need further context-based examination. The findings and the PA insights suggested the need for a systematic, integrated, incentive-based solution approach using the transdisciplinary concepts of agile project management, frugal re-engineering and business model development. Further research should develop the systematic approach with specific project stages, work plans, objectives and methods. The established concept should then be evaluated and improved on the field using action research methodology.

\section{References}

[1] Pearce, J., Albritton, S., Grant, G., Steed, G., \& Zelenika, I., A new model for enabling innovation in appropriate technology for sustainable development. Sustainability: Science, Practice, \& Policy, 8(2), pp. 901-902, 2012.

[2] Sianipar, C. P. M., Dowaki, K., \& Yudoko, G., Technological solution for vulnerable communities: How does its approach matter? IOP Conference Series: Materials Science and Engineering, 58(1), pp. 12-22, 2014.

[3] Murphy, H. M., McBean, E. A., \& Farahbakhsh, K., Appropriate technology - A comprehensive approach for water and sanitation in the developing world. Technology in Society, 31(2), pp. 158-167, 2009.

[4] Poverty Overview, The World Bank Website, Washington DC, www.worldbank.org/en/topic/poverty/overview.

[5] Terrapon-Pfaff, J., Dienst, C., König, J., \& Ortiz, W., A cross-sectional review: Impacts and sustainability of small-scale renewable energy projects in developing countries. Renewable and Sustainable Energy Reviews, 40, pp. 1-10, 2014.

[6] Reymond, P., Planning Integrated Faecal Sludge Management Systems (Chapter 17). Faecal Sludge Management: Systems Approach for Implementation and Operation, IWA Publishing, pp. 363-387, 2014.

[7] Pueyo, A., Enabling frameworks for low-carbon TT to small emerging economies: Analysis of ten case studies in Chile. Energy Policy, 53, pp. 370-380, 2013.

[8] IPCC, Methodological and Technological Issues in Technology Transfer, A Special Report of IPCC Working Group III, 2000. 
[9] Liu, H., \& Liang, X., Strategy for promoting low-carbon TT to developing countries: The case of CCS. Energy Policy, 39(6), pp. 3106-3116, 2011.

[10] Klintenberg, P., Wallin, F., \& Azimoh, L. C., Successful TT: What does it take? Applied Energy, 130, pp. 807-813, 2014.

[11] Strande, L., Ronteltap, M., \& Brdjanovic, D. (eds.), Faecal sludge management: Systems approach for implementation and operation. IWA Publishing, 2014.

[12] Nikiema, J., Figoli, A., Weissenbacher, N., Langergraber, G., Marrot, B., \& Moulin, P., Wastewater treatment practices in Africa-experiences from seven countries, 2013.

[13] Starkl, M., Brunner, N., \& Stenström, T. A., Why do water and sanitation systems for the poor still fail? Policy analysis in economically advanced developing countries. Environmental science \& technology, 47(12), pp. 6102-6110, 2013.

[14] Schillebeeckx, S.J., Parikh, P., Bansal, R., \& George, G., An integrated framework for rural electrification: Adopting a user-centric approach to business model development. Energy Policy, 48, pp. 687-697, 2012.

[15] European Court of Auditors, "Water and sanitation projects in sub-Saharan Africa - EU Commission could and should do better". EU Auditors, 2012.

[16] Appropedia, http://www.appropedia.org/.

[17] Akvopedia, http://akvopedia.org/wiki/.

[18] Africa Internet Users, Facebook and Population Statistics, www.internetworldstats.com/stats1.htm.

[19] Eisenhardt, K. M., Agency theory: An assessment and review. Academy of management review, 14(1), pp. 57-74, 1989.

[20] Schabbel, C., The value chain of foreign aid: development, poverty reduction, and regional conditions. Springer Science \& Business Media, pp. 77-79, 2007.

[21] Altmann, M. P., Contextual Development Economics: A Holistic Approach to the Understanding of Economic Activity in Low-Income Countries (Vol. 8). Springer Science \& Business Media, pp. 169-174, 2010.

[22] Yin, R. K., Case Study Research: Design and Methods. 4th Edition. Sage Publications, 2003.

[23] BORDA,www.borda-net.org/.

[24] AKSANSI, http://aksansi.org/en/.

[25] Cervone, H. F., Understanding agile project management methods using Scrum. OCLC Systems \& Services: International digital library perspectives, 27(1), pp. 18-22, 2011.

[26] Sehgal, V., Dehoff, K., \& Panneer, G., The importance of frugal engineering. Strategy+ Business, 59, pp. 1-5, 2010.

[27] Ahlstrom, D., Innovation and growth: How business contributes to society. The Academy of Management Perspectives, 24(3), pp. 11-24, 2010.

[28] Bocken, N. M. P., Short, S. W., Rana, P., \& Evans, S., A literature and practice review to develop sustainable business model archetypes. Journal of cleaner production, 65, pp. 42-56, 2014. 